\title{
Trends in the epidemiology of erysipelas in Slovenia
}

\author{
Katarina Sočan ${ }^{1}$, Maja Sočan²凶
}

\begin{abstract}
Introduction: Erysipelas is a common infection of the skin and subcutaneous tissue. Despite the relative frequency of erysipelas, data on its basic epidemiological characteristics are scant. This study describes the trends in erysipelas epidemiology in Slovenia. Methods: Data on notified erysipelas cases from 2000 to 2016 were extracted from the electronic database of reportable communicable diseases and analyzed.

Results: There were 36,254 notified cases during the observed time period of 17 years. The yearly age-standardized incidence rate of erysipelas increased from 71.5 per 100,000 in 2000 to 111.3 per 100,000 in 2016 , with the main rise in the $\geq 75$ age group. Erysipelas was more common in women, but the sex-related difference lessened in the period observed. The hospitalization rate declined. Erysipelas was significantly more frequent in the warmer period of the year. The correlation between erysipelas incidence and average monthly temperature was stronger in the $\leq 64$ age group than in the $\geq 65$ age group.

Conclusion: Retrospective observational data confirmed a rising trend in erysipelas cases, especially among the elderly. Aging of the population will continue to increase the burden of the disease, unless health promotion and prevention lowers the prevalence of the risk factors.
\end{abstract}

Keywords: erysipelas, epidemiology, Slovenia

Received: 10 August 2017 | Returned for modification: 3 October 2017| Accepted: 8 November 2017

\section{Introduction}

Erysipelas is a relatively common infection of the upper dermis and superficial lymphatics. The affected area is tender and intensely erythematous, with a clearly demarcated margin with regional lymphadenopathy (1). Erysipelas most commonly involves the lower extremities or the face. Local skin affection is associated with general signs and symptoms such as malaise, nausea, chills, and fever. The diagnosis is based on clinical signs (2). Bacteriological sampling is rarely performed in day-to-day clinical practice. The sensitivity of skin cultures in erysipelas is considered low (less than 40\%). Group A $\beta$-hemolytic streptococci are thought to be the most frequent cause of erysipelas, with some recent studies showing the importance of groups B, C, and G streptococci, Staphylococcus aureus, and other bacteria (3).

The predisposing factors for erysipelas are disruption of the cutaneous barrier (dermatophytosis and chronic ulcers of the skin), venous insufficiency, obesity, diabetes mellitus, heart failure, and previous surgery (4-9). Cellulitis-infection of the dermis and subcutaneous fat-cannot always be differentiated from erysipelas. The advancing border of cellulitis tends to be rather indistinct compared to erysipelas, which presents with a raised, distinct border. Cellulitis and erysipelas can result in local necrosis and abscess formation (10).

Most cases are treated at the primary care level because patients with uncomplicated erysipelas adequately respond to antibiotics. Referral to the secondary level of care is rarely necessary (11). Complications are expected in the elderly and in patients with chronic diseases; for example, diabetes mellitus, alcoholism, and cardiovascular diseases. Despite the frequency of erysipelas, there is a paucity of recent epidemiological studies, with most studies performed in hospital settings with practically no data from the primary level of care $(6,12)$.

This study presents the descriptive epidemiology of notified erysipelas cases from 2000 to 2016 in Slovenia.

\section{Patients and methods}

Data on notified erysipelas cases from 2000 to 2016 were extracted from the SURVIVAL electronic database of reportable communicable diseases. Erysipelas is listed as one of the case-based mandatory notifiable communicable disease from 1977 onwards. According to the Rules on Reporting Communicable Diseases, the data reported include demographics (age and sex), the date of onset of the illness, microbiological confirmation of diagnosis, hospitalization, and outcome (13). According to the legislation, primary, secondary, or tertiary-care physicians are obligated to report cases of erysipelas. The cases are mostly reported in paper form, and in recent years some institutions have reported them electronically. Reporting in paper form is likely to be an obstacle to completeness of the data. Data are checked at the regional and national levels for consistency and duplicates are deleted.

Laboratory confirmation has not been attempted in most cases. According to the Definition of Notifiable Communicable Diseases, most erysipelas cases have been classified as probable and not confirmed cases because diagnosis has relied on clinical presentation only (14).

The yearly crude and age-standardized erysipelas incidence rate per 100,000 inhabitants for the age groups 0-49, 50-64, $65-74$, and $\geq 75$ were calculated. A direct standardization method was used to compare the erysipelas incidence rate over a longer period of time, in which the age structure changed to avoid the possibility of having different frequency distributions attributed to the aging of the population. The Slovenian standard population (2002 census) was used as recommended by SLORA (http:// www.slora.si/en/definicije-kazalnikov-in-metod).

Monthly average temperatures were provided by the Slovenian Environment Agency and were extracted from the webpages of the 
Slovenian Statistical Office. The correlation between erysipelas incidence and average temperature was calculated using the Pearson correlation coefficient.

\section{Results}

From 2000 to 2016, the Slovenian national surveillance system received 36,254 erysipelas notifications. During the observed time period of 17 years, there was a noticeable increase in reported erysipelas cases (from 1,399 cases in 2000 to 2,397 cases in 2016). The yearly age-standardized incidence rate of erysipelas increased from 71.5 per 100,000 in 2000 to 111.3 per 100,000 in 2016 (Table 1).

An increase was noted in all age groups, but it was most pronounced in the age group $\geq 75$ (a 70\% increase) and was the smallest in the age group 50-64 (a 6\% increase; Fig. 1).

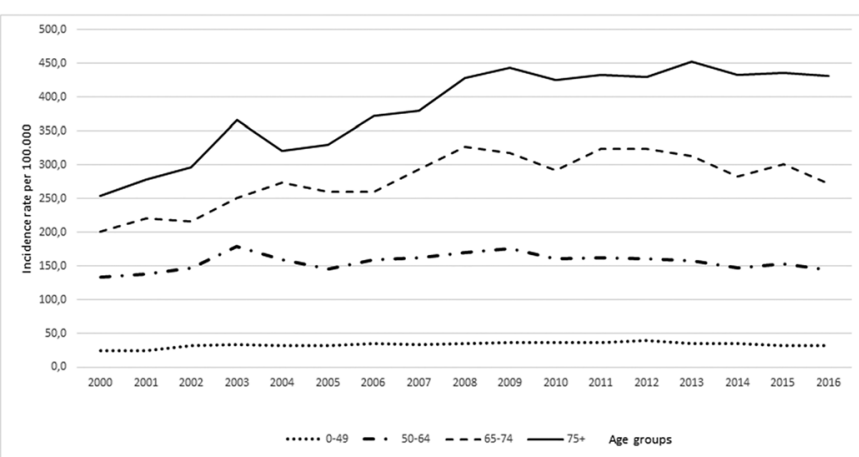

Figure 1 | Notified erysipelas incidence rates by age group, 0-49, 50-64, 65-74, and 75+, Slovenia, 2000-2016.

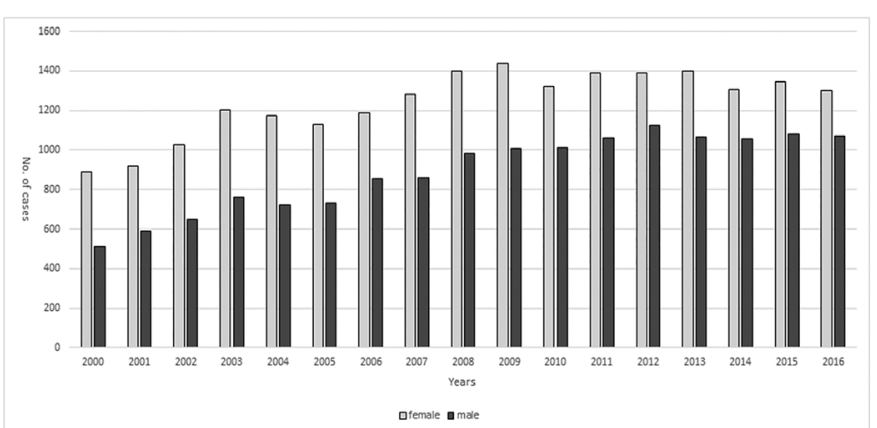

Figure 2 | Notified erysipelas cases by sex, Slovenia, 2000-2016.
Overall, erysipelas was more frequently notified in females $(21,105$ cases, $58.2 \%)$ than in males $(15,149$ cases, $41.8 \%)$. The male-to-female ratio changed from 2000 to 2017 in favor of males; the percentage of female cases dropped slowly but constantly, as shown in Fig. 2.

The incidence rate was higher in females in the age groups $65-74$ and $\geq 75$ during the entire period surveyed. In the age group 50-64, the erysipelas incidence rate was higher in females from 2000 to 2011 and in 2016, and slightly lower from 2012 to 2015. Interestingly, in the age group o-49, the incidence rate was found to be higher in male patients, with an increasing divergence between the sexes over the years.

The percentage of patients treated as outpatients increased; less than $5 \%$ of all notified cases were admitted to the hospital in 2016. As expected, the hospitalization rate rose with increasing age, with no difference observed between men and women.

The data revealed a typical seasonal pattern of erysipelas. Half of the cases occurred from June to September or from May to August, depending on the temperature conditions in specific months. Spearman's correlation coefficient between temperature and the number of cases was 0.74 in all age groups. The correlation for patients $\leq 64$ years old (o.8) was stronger than that for patients $\geq 65$ years old (o.6).

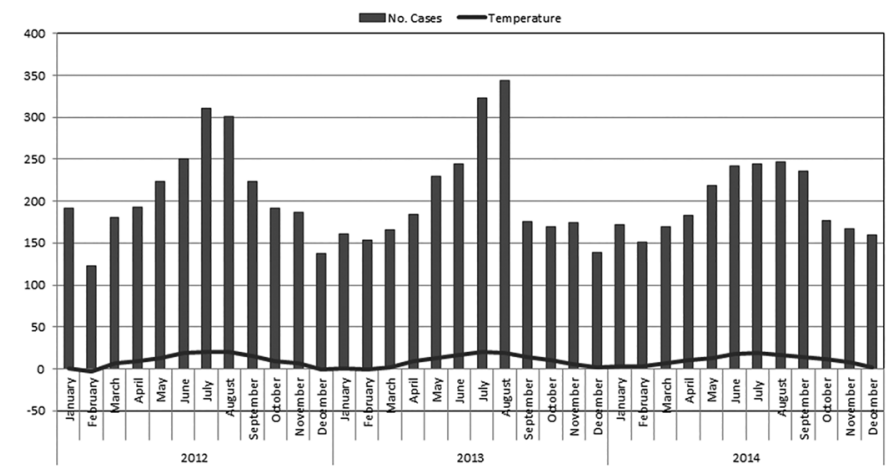

Figure 3 | Monthly number of notified erysipelas cases and average monthly temperature, Slovenia, 2012-2014.

\section{Discussion}

The findings of a retrospective analysis performed on surveillance data revealed the key epidemiological trends for erysipelas in Slo-

Table 1 | Crude and standardized number of erysipelas cases and incidence rates per 100,000 population, Slovenia, $2000-2016$.

\begin{tabular}{|c|c|c|c|c|c|c|}
\hline Year & $\begin{array}{c}\text { No. of cases } \\
\text { (incidence rate) }\end{array}$ & $\begin{array}{l}\text { Standardized no. of } \\
\text { cases (incidence rate) }\end{array}$ & $\begin{array}{l}\text { No. of female cases } \\
\text { (incidence rate) }\end{array}$ & $\begin{array}{l}\text { Standardized no. of } \\
\text { female cases } \\
\text { (incidence rate) }\end{array}$ & $\begin{array}{l}\text { No. of male cases } \\
\text { (incidence rate) }\end{array}$ & $\begin{array}{c}\text { Standardized no. of } \\
\text { male cases } \\
\text { (incidence rate) }\end{array}$ \\
\hline 2000 & $1,399(70.8)$ & $1412.9(71.5)$ & $889(87.2)$ & $889.2(87.2)$ & $510(53.2)$ & $519.7(54.3)$ \\
\hline 2001 & $1,508(75.7)$ & $1510.8(75.8)$ & $918(90.1)$ & $919.1(90.3)$ & $590(60.6)$ & $591.5(60.7)$ \\
\hline 2002 & $1,675(83.9)$ & $1675.0(83.9)$ & $1,028(100.8)$ & $1028.0(100.8)$ & $647(66.3)$ & $647.0(66.3)$ \\
\hline 2003 & $1,966(98.5)$ & $1964.9(98.4)$ & $1,202(117.9)$ & $1202.3(118.0)$ & $764(78.2)$ & $762.9(78.1)$ \\
\hline 2004 & $1,897(95.0)$ & $1895.8(94.9)$ & $1,174(115.1)$ & $1173.6(115.1)$ & $723(74.0)$ & $722.3(73.9)$ \\
\hline 2005 & $1,865(93.2)$ & $1859.9(92.9)$ & $1,130(110.7)$ & $1128.4(110.5)$ & $735(75.0)$ & $732.0(74.7)$ \\
\hline 2006 & $2,046(101.9)$ & $2033.0(101.2)$ & $1,190(116.4)$ & $1186.5(116.0)$ & $856(86.8)$ & $847.5(86.0)$ \\
\hline 2007 & $2,143(106.1)$ & $2117.9(104.9)$ & $1,282(125.2)$ & $1276.1(124.6)$ & $861(86.5)$ & $844.5(84.9)$ \\
\hline 2008 & $2,380(116.7)$ & $2329.0(114.2)$ & $1,399(136.2)$ & $1388.8(135.2)$ & 981 (96.9) & $945.9(93.4)$ \\
\hline 2009 & $2,447(119.8)$ & $2391.1(117.1)$ & $1,440(139.7)$ & $1424.7(138.2)$ & $1,007(99.5)$ & $971.5(96.0)$ \\
\hline 2010 & $2,332(113.8)$ & $2271.1(110.8)$ & $1,320(127.6)$ & $1300.9(125.7)$ & $1,012(99.7)$ & 973.5 (95.9) \\
\hline 2011 & $2,451(119.4)$ & $2383.2(116.1)$ & $1,388(133.8)$ & $1346.6(131.6)$ & $1,063(104.7)$ & $1021.8(100.6)$ \\
\hline 2012 & $2,511(122.1)$ & $2437.1(118.5)$ & $1,388(133.6)$ & $1362.3(131.1)$ & $1,123(110.4)$ & $1077.4(105.9)$ \\
\hline 2013 & $2,464(119.7)$ & $2388.5(116.0)$ & $1,399(134.6)$ & $1372.3(132.0)$ & $1,065(104.4)$ & $1019.5(100.0)$ \\
\hline 2014 & $2,364(114.7)$ & $2289.0(110.0)$ & $1,308(125.7)$ & $1282.1(123.3)$ & $1,056(103.4)$ & $1009.2(98.8)$ \\
\hline 2015 & $2,429(117.7)$ & $2349.9(113.9)$ & $1,346(129.4)$ & $1318.9(126.8)$ & $1,083(105.9)$ & $1033.8(101.1)$ \\
\hline 2016 & $2,377(115.2)$ & $2298.1(111.3)$ & $1,304(125.3)$ & $1277.9(122.8)$ & $1,073(104.8)$ & $1022.9(99.9)$ \\
\hline
\end{tabular}


venia. In recent years, the erysipelas incidence rate has mostly been rising among the elderly: the disease was more common in females, was rarely confirmed microbiologically, and has a pronounced seasonal pattern.

The population-based data on erysipelas are scant. Most studies were observational and included data from hospitalized patients with erysipelas $(3-5,8,12,15)$. Admission to a hospital is required in more severe, complicated erysipelas cases, and may not reflect all aspects of epidemiology in a specific population. Slovenian surveillance data are comparable to the study performed by Bartholomeeusen et al. in the Netherlands (6). An increase in erysipelas cases over the years has been observed in this Dutch study, including only patients treated at the primary level of care. In a 10-year period, the incidence rate increased from 1.74 to 2.43 per 1,000 patients, with the highest upsurge in the $\geq 75$ group (6), which is in agreement with the findings of this study. An increasing trend for erysipelas (a notifiable disease) has been found in the Czech Republic; there was an increase in the incidence rate from 25 to 35 per 100,000 inhabitants (16), which was only onethird of the reported incidence rate in Slovenia.

In hospital-based studies from Spain (15) and Sweden (3), a slight male preponderance in erysipelas cases was found, whereas in two other studies females marginally outnumbered males $(8,12)$. In one study, significantly more women with erysipelas were admitted to the hospital than men (17). The only study from primary care failed to reveal any sex difference (6). Of note, the data from this study indicated higher incidence rates in females (except in the age group o-49), with a diminishing sex difference over the years. The prevalence of risk factors such as obesity, diabetes mellitus, chronic venous disorders of the lower limbs, and dermatophytosis may vary between populations, with a subsequently different sex distribution of erysipelas. Epidemiological studies confirmed the higher frequency of venous diseases of the lower extremities in women compared to men, which might explain the higher incidence in this study (18). However, obesity and diabetes mellitus are increasingly more frequent in males, which may explain the decrease in the sex difference (19).

According to a Dutch study, only one out of 14 erysipelas patients needed inpatient care (11). The erysipelas hospitalization rate dropped considerably in Slovenia. These findings are in line with the general trend of more stringent criteria for hospital admission, shortage of hospital beds, and financial restrictions in healthcare.

Most recent studies from temperate climate zones have found more erysipelas cases during the summer $(6,8,17,20)$. It might be speculated that higher temperatures predispose the development of dermatophytosis, enhance venous and lymphatic stasis, and favor skin fissures as points of bacterial entry to upper dermis. No seasonal variation has been found by others, or there have been more cases in spring and autumn $(21,22)$. A trend for increased episodes of facial erysipelas during autumn and winter was noted by Krasagakis (10). A possible explanation is that the seasonality of facial erysipelas is linked to a higher frequency of respiratory tract infections.

The main limitation of this study is the inherent weakness of the data. Most cases were classified as erysipelas on clinical grounds only. Erysipelas cannot always be distinctly distinguished from cellulitis, which is a deeper infection of the skin; a clearly demarcated edge of the erysipelas is considered a typical feature of the disease. The misclassification of a certain number of cases is undoubtedly an issue. The current surveillance system does not allow separation between the first episode of erysipelas and the recurrent case of the disease, which is a weakness in the study.

Bacteriological sampling is rarely demanded at the primary care level. Even in hospitalized patients, microbiological specimens are rarely collected. Patients subjected to blood culturing have significantly more often a serious disease and/or underlying illness. In one large retrospective study from Sweden, microbiological specimens were taken from approximately $30 \%$ of patients with erysipelas, out of which $72 \%$ were positive for Staphylococcus aureus (most often isolated in pure culture) (3). Staphylococcus aureus was the most common pathogen identified in hospitalized patients in a Greek study (8). Group A $\beta$-hemolytic streptococci, followed by groups B, C, and G streptococci, are usually cited as the most common causes of erysipelas (2), which is a discrepancy in the studies mentioned above. It would be interesting to study the etiology of erysipelas in primary care settings, but this would be difficult to perform for practical reasons (6). Data from our retrospective analysis of notified cases did not add any new knowledge to the etiology of erysipelas.

Underreporting of erysipelas cases might present a barrier to attaining high quality and comprehensive data for prospective studies. The aim of this study was to display trends in the age/sex distribution and seasonality, and that goal was achieved. The incidence rate is most probably underestimated due to incomplete notification.

To conclude, the aging population will continue to increase the burden of erysipelas, unless health promotion and prevention lower the prevalence of the risk factors.

\section{References}

1. Bonnetblanc JM, Bédane C. Erysipelas: recognition and management. Am J Clin Dermatol. 2003;4:157-63.

2. Celestin R, Brown J, Kihiczak G, Schwartz RA. Erysipelas: a common potentially dangerous infection. Acta Dermatovenerol Alp Pannonica Adriat. 2007;16:1237 .

3. Bläckberg A, Trell K, Rasmussen M. Erysipelas, a large retrospective study of aetiology and clinical presentation. BMC Infect Dis. 2015;15:402.

4. Dupuy A, Benchikhi H, Roujeau JC, Bernard P, Vaillant L, Chosidow O, et al. Risk factors for erysipelas of the leg (cellulitis): case-control study. BMJ. 1999;318:1591-4.

5. Mokni M, Dupuy A, Denguezli M, Dhaoui R, Bouassida S, Amri M, et al. Risk factors for erysipelas of the leg in Tunisia: a multicenter case-control study. Dermatology. 2006;212:108-12.

6. Bartholomeeusen S, Vandenbroucke J, Truyers C, Buntinx F. Epidemiology and comorbidity of erysipelas in primary care. Dermatology. 2007;215:118-22.
7. Harpsøe MC, Nielsen NM, Friis-Møller N, Andersson M, Wohlfahrt J, Linneberg $A$, et al. Body mass index and risk of infections among women in the Danish national birth cohort. Am J Epidemiol. 2016;183:1008-17.

8. Krasagakis K, Valachis A, Maniatakis P, Krüger-Krasagakis S, Samonis G, Tosca AD. Analysis of epidemiology, clinical features and management of erysipelas. Int J Dermatol. 2010;49:1012-7.

9. Pereira de Godoy JM, Azoubel LM, Guerreiro Godoy M de F. Erysipelas and lymphangitis in patients undergoing lymphedema treatment after breast-cancer therapy. Acta Dermatovenerol Alp Pannonica Adriat. 2009;18:63-5.

10. Krasagakis K, Samonis G, Valachis A, Maniatakis P, Evangelou G, Tosca A. Loca complications of erysipelas: a study of associated risk factors. Clin Exp Dermatol. 2011;36:351-4.

11. Goettsch WG, Bouwes Bavinck JN, Herings RM. Burden of illness of bacterial cellulitis and erysipelas of the leg in the Netherlands. J Eur Acad Dermatol Venereol. 2006;20:834-9. 
12. Kozłowska D, Myśliwiec H, Kiluk P, Baran A, Milewska AJ, Flisiak I. Clinical and epidemiological assessment of patients hospitalized for primary and recurrent erysipelas. Przegl Epidemiol. 2016;70:575-84.

13. Anon. Rules on communicable diseases and specific measures for their prevention and control. Official Gazette of the Republic of Slovenia no. 022-32/98-99. Slovene.

14. Sočan M, Šubelj M. Definitions of reportable communicable diseases for epidemiological surveillance. National Institute of Public Health, Ljubljana, May 2012. [Cited 24 July 2017] Available from: http://www.nijz.si/sites/www.nijz. si/files/uploaded/definicija_prijavljivih_nb_za_namene_epi_spremljanja.pdf. Slovene.

15. Perelló-Alzamora MR, Santos-Duran JC, Sánchez-Barba M, Cañueto J, Marcos M, Unamuno P. Clinical and epidemiological characteristics of adult patients hospitalized for erysipelas and cellulitis. Eur J Clin Microbiol Infect Dis. 2012;31:214752.

16. Hubálek Z. North Atlantic weather oscillation and human infectious diseases in the Czech Republic, 1951-2003. Eur J Epidemiol. 2005;20:263-70.
17. Wojas-Pelc A, Alekseenko A, Jaworek AK. Erysipelas-course of disease, recurrence, complications; a 10 years retrospective study. Przegl Epidemiol. 2007;61: 457-64.

18. Lohr JM, Bush RL. Venous disease in women: epidemiology, manifestations, and treatment. J Vasc Surg. 2013;57:37S-45S.

19. National Institute of Public Health. Challenges in life style improvement and health-ten years of CINDI in Slovenia. NIPH, 2014. [Cited 19 October 2017] Available from: http://www.nijz.si/sites/www.nijz.si/files/publikacije-datoteke/ izzivi_desetletje_cindi_14.pdf.

20. Pereira de Godoy JM, Galacini Massari P, Yoshino Rosinha M, Marinelli Brandão R, Foroni Casas AL. Epidemiological data and comorbidities of 428 patients hospitalized with erysipelas. Angiology. 2010;61:492-4.

21. Jorup-Rönström C. Epidemiological, bacteriological and complicating features of erysipelas. Scand J Infect Dis. 1986;18:519-24.

22. Crickx B, Chevron F, Sigal-Nahum M, Bilet S, Faucher F, Picard C, et al. Erysipelas: epidemiological, clinical and therapeutic data. Ann Dermatol Venereol. 1991;118:11-6. 